\title{
СОВРЕМЕННЫЕ НАПРАВЛЕНИЯ РАЗВИТИЯ КОНТРОЛЯ НА КРУПНОМ ПРОМЫШЛЕННОМ ПРЕДПРИЯТИИ
}

\section{MODERN DIRECTIONS OF CONTROL DEVELOPMENT AT A LARGE INDUSTRIAL ENTERPRISE}

\section{T. Goremykina N. Trishkina}

Summary. The article presents the current trends in the development of control at a large industrial enterprise. The advanced experience in this field has been synthesized, and promising areas for the formation of an integrative control system have been identified. Based on the survey method, the main problems of control in large manufacturing enterprises of 15 regions of Russia were identified, practical recommendations were proposed for building an integrative control system on an independent and highly professional basis, including internal control, internal audit and controlling, and covering all key business processes with applying the latest digital era.

Keywords: control, controlling, internal audit, digitalization, management of a large industrial enterprise, manufacturing industry.
B современных социально-экономических условиях одним из ключевых направлений управления крупными промышленными предприятиями выступает формирование системы интегративного контроля, охватывающей все направления функционирования предприятия и обеспечивающая постоянные улучшения ключевых бизнес-процессов на основе непрерывного мониторинга, анализа и применения корректирующих воздействий.

Формирование интегративных систем контроля на отечественных промышленных предприятиях выступает исключительно важной новацией в условиях нового технологического уклада, когда конкурентоспособность и стратегическое развитие предприятий в полной мере зависят от активизации резервов инноватики, выявление которых нередко происходит при реализации мер и инструментов контроля. Другой аспект, обусловливающий практический интерес к построению инте-
Горемыкина Татьяна Константиновна

К.э.н., Московский международный университет 5149611@mail.ru

Тришкина Надежда Антоновна

К.э.н., Московский международный университет ntrishkina@list.ru

Аннотация. В статье представлены современные направления развития контроля на крупном промышленном предприятии. Синтезирован передовой опыт в данной сфере, определены перспективные направления формирования интегративной системы контроля. На основе метода опроса, выявлены основные проблемы контроля на крупных предприятиях обрабатывающей промышленности 15 регионов России, предложены практические рекомендации по построению интегративной системы контроля на независимой и высоко профессиональной основе, включающей внутренний контроль, внутренний аудит и контроллинг, и охватывающей все ключевые бизнес-процессы с применением последних цифровой эпохи.

Ключевые слова: контроль, контроллинг, внутренний аудит, цифровизация, управление крупным промышленным предприятием, обрабатывающая промышленность.

гративных систем контроля на промышленных предприятиях - проблематика поиска внутренних источников обеспечения устойчивого функционирования в условиях турбулентной внешней среды, включая негативное воздействие антироссийских санкций на развитие целых отраслей промышленности и необходимость мобилизации всех ресурсов для успешного решения задач импортозамещения.

Проблема исследования заключается в том, что, несмотря на функционирование систем контроля, внутреннего аудита и контроллинга на современных крупных промышленных предприятиях в России, интеграция данных систем практически всегда или отсутствует, или осуществлена на ненадлежащем уровне. Кроме того, контролю (контроллингу) и/или аудиту подчинены далеко не все ключевые бизнес-процессы предприятия, идентификация последних нередко не осуществлена. Управление контролем не подчинено стратегическим 
целям и философии развития предприятия, а цифровые технологии в данной сфере практически не внедряются. В своей совокупности, наличие приведенных проблем не просто сдерживает развитие отечественной промышленности (как в целом, так и конкретных предприятий), но также все в большей степени выводит предприятия на обочину глобальной конкуренции в условиях нового технологического уклада.

Приведенная совокупность проблем требует скорейшего разрешения, однако системный характер, который должен быть обеспечен для целей эффективной организации контроля, не требует поспешности при разработке и реализации соответствующих организационных решений; скорее, наоборот,- необходимо изучить и систематизировать наилучшие управленческие практики, зарубежный опыт; затем, провести детальную идентификацию существующих проблем, по результатам чего разработать перспективные управленческие решения, оценить их эффективность и потенциал, после чего уже воплощать в жизнь.

Принятие управленческого решения, как правило, начинается с осознания наличия проблемы, требующей решения, либо открывающихся возможностей, использование которых предполагает принятие мер управленческого характера. В самом общем виде процедура принятия управленческих решений включает следующие основные этапы:

1. Диагностика проблемы и анализ ситуации

2. Разработка и формулирование вариантов решения проблемы.

3. Определение критериев сравнения альтернатив и выбор наилучшей, исходя из поставленных целей.

4. Организационная подготовка, согласование и реализация управленческого решения.

5. Оценка эффективности результатов реализации управленческого решения. [3]

Для того, чтобы в ходе управленческого решения были достигнуты поставленные цели, успешно реализовались задачи, на наш взгляд, внедрение в деятельность предприятия таких процедур как внутренний контроль и внутренний аудит на четвертом этапе принятия управленческого решения, является необходимым условием их успешной реализации.

Цель внутреннего контроля - информационное обеспечение системы управления для получения возможности принятия эффективных решений.

Успешность применения внутреннего контроля предприятий обеспечивается экономической, административной и дисциплинарной ответственностью руководителей структурных подразделений за ненадлежащее выполнение контрольных функций. Условия и порядок осуществления внутреннего контроля подлежит документальному оформлению, дисциплина ведения и обязанности определяются руководителем организации.

Исследованные аспекты зарубежной практики организации контроля на крупных промышленных предприятиях позволяют сделать следующие выводы о тенденциях, по сути, ставших уже управленческим мейнстримом [1, 3-8]:

- на крупных промышленных предприятиях, с учетом размера и специфики функционирования данных сложнейших социально-экономических систем, системы контроля включают собственно контроль, аудит, а также контроллинг всех ключевых бизнес-процессов;

- контроль осуществляется как подразделениями самого предприятия (внутренний), так и сторонними учреждениями, и организациями (внешний). Организационно независимые частные промышленные предприятия подлежат внешнему контролю со стороны государственных органов, а также для различных целей могут прибегать к инициативному внешнему аудиту. В отдельных случаях, в частности, для подтверждения следования менеджмента предприятия принятым на себя обязательствам в сфере надлежащих производственных практик (good manufactury practices; наиболее характерно для пищевой, фармацевтической промышленности), внешний аудит могут проводить контрагенты предприятия;

- внутренний контроль от внутреннего аудита отличают, прежде всего, объект, процессы и результаты, хотя по конкретным процедурам они могут практически совпадать. Контроль проводится в отношении текущей деятельности крупного промышленного предприятия, а аудит - по результатам функционирования за определенный период. Контроль призван, прежде всего, своевременно выявлять ошибки и проблемы функционирования предприятия и обеспечивать их оперативное устранение, а аудит предполагает разработку заключений, по результатам которых предлагаются решения как по поводу устранения выявленных нарушений и недопущения их в будущем, так и по поводу совершенствования деятельности предприятий в целом;

- контроллинг, В свою очередь, это «комплексная система для управления предприятием, с возможностью, координации взаимодействия систем контроля эффективности и систем менеджмента с возможностью снижения централизованного администрирования. Эта же система 
должна позволять поддерживать информационно-аналитическим способом процессы принятия решений при управлении» [2, с.24];

- контроль, аудит и контроллинг, тем самым, три самостоятельных направления внутренней контрольной деятельности на крупном промышленном предприятии, однако, поскольку все они опосредуют реализацию единой философии контроля, то лишь за счет их интеграции можно обеспечить достижение предопределенного эффекта;

- контроль на крупном промышленном предприятии должен охватывать все ключевые бизнес-процессы. Безусловно, традиционно развивался, прежде всего, производственный контроль и контроль за качеством выпускаемой продукции. Однако, для достижения успешного, безопасного и эффективного функционирования современного крупного промышленного предприятия, контролю должны быть подвержены все ключевые бизнес-процессы, как в сфере производства, так и вне ее. По целому ряду бизнес-процессов - и здесь особняком уже выступают производственные процессы - контроль может быть осуществлен, во-первых, в режиме постоянного функционирования, и, во-вторых, с частичной или его автоматизацией. Подобный контроль именуется мониторингом [4];

- аудит (внутренний) также не стоит отождествлять исключительно со сферой финансов, как порой это делают менеджеры. Безусловно, аудит произошел из финансовой и учетной сферы, однако, опять же, в современных условиях с применением методов, инструментов и технологий аудита представляется возможным обеспечить интегральное повышение надежности и качества реализации всех ключевых бизнес-процессов;

- парадигма интегративного контроля включает в себя идею объединения направлений и разновидностей внутренней контрольной деятельности (контроль (мониторинг), аудит и контроллинг) в единую систему [4]. Реализация данной идеи обеспечивается за счет:

- во-первых, подчинения системы внутреннего контроля целям и задачам стратегического развития крупного промышленного предприятия;

- во-вторых, обеспечения исключительной организационной независимости системы контроля, к примеру, через подчинения ее напрямую Совету директоров предприятия;

- в-третьих, посредством унификации методологии контрольной деятельности, основу которой должен составлять риск-ориентированный подход, позволяющий более эффективно распределять ресурсы и осуществлять мероприятия по тем направлениям деятельности, бизнес-процессам, где наиболее высока вероятность проблем, ошибок и нарушений;

- в-четвертых, за счет профессионализации управления.

Внутренний контроль и внутренний аудит должны осуществлять специализированные и обособленные подразделения крупного промышленного предприятия, укомплектованные достаточным числом профессионалов, в отношении которых обеспечивается непрерывное повышение компетенций;

В современных условиях качество интегративного контроля на крупных промышленных предприятиях обеспечивается путем цифровизации контроля [5-8]. Цифровые инструменты и методы позволяют автоматизировать многие процессы и процедуры, не только содействуя рациональному распределению ресурсов, но также нивелируя негативное влияние человеческого фактора на контроль.

Под внутренним контролем следует понимать процесс, направленный на проверку и оценку собственной работы, осуществляемой в собственных интересах для получения уверенности в эффективности и конструктивности своей деятельности. [2] Наличие в компании системы внутреннего контроля, как показывает практика, становится все более неотъемлемым условием стабилизации и повышения финансовых показателей, принятия качественных управленческих решений.

Оценка и диагностика финансово-хозяйственной деятельности предприятия является также функцией системы внутреннего контроля, основывающаяся на методиках и процедурах, принятых управленческими структурами и направленная на достижение конечных результатов и поставленных задач. Следует отметить, что результативность деятельности организации во многом зависит от эффективности постоянных контрольных мероприятий, зависящих от характера и масштабов её деятельности, должна внедряться во все уровни управления и структурные подразделения. В осуществление контрольных мероприятий должны быть вовлечены и принимать непосредственное участие все сотрудники организации в соответствии с их полномочиями. Необходимо акцентировать, что при внедрении в систему управления организации внутреннего контроля, контроллинга, и внутреннего аудита должна быть получена экономическая эффективность (сопоставление результатов и затрат).

Следует акцентировать внимание на значении контроллинга для успешного выполнения запланированных рубежных показателей предприятий. Контроллинг, 
наряду с такими функциями как планирование, принятие управленческих решений, учет и контроль призван выполнять информационно-аналитическую функцию, зачастую недооцененную в практической работе, а также в теоретических работах.

Информационно- аналитическая система охватывает все необходимые сведения: производительность, затраты, результаты, поэтому какие бы методы принятия управленческих решений не применялись на предприятии, какие бы принципы не были заложены в основу их принятия, эффект не будет достигнут, если используемая информационно-аналитическая база была недостаточной и сводилась только к констатации фактов.

Наиболее значимыми проблемами аналитической функции контроллинга, на наш взгляд, вырисовываются две проблемы: недооценка значимости аналитической работы и недостатки в ее организации и проведении и вторая - недостатки методического характера в комплексном экономическом анализе.

Недопонимание руководством необходимости аналитической работы приводит к недостатку информации для принятия экономически обоснованных оптимальных решений, и в условиях постоянной оптимизации затрат на содержание аппарата управления под сокращение или свертывание одними из первых попадают информационно-аналитические службы предприятия.

Что касается второй группы проблем, связанных с недостатками методического характера в комплексном экономическом анализе, то их также накопилось весьма значительное количество. Это относится и к методике проведения комплексного экономического анализа, и к использованию или, наоборот, к отказу от использования в аналитической практике ряда важных показателей.

Так, часто нехватка квалификации или времени для освоения новых методик и показателей анализа хозяй- ственно-финансовой деятельности предприятия приводит к неверной оценке хозяйственных процессов. [3]

В ходе подготовки настоящей публикации, нами был проведен опрос топ-менеджеров 68 предприятий обрабатывающей промышленности нашей страны, представлявших 15 регионов и 14 видов экономической деятельности, что обеспечивало высокую репрезентативность выборки.

В ходе опроса выявлено следующее:

- ни на одном из предприятий не сформирована интегративная система контроля;

- в 94\% случаев (58 предприятий), внутренний аудит не проводится;

- в 97\% случаев (60 предприятий), системы контроля / аудита не обладают организационной независимостью;

- в 73\% случаев (45 предприятий), контроль касается только производственной деятельности, качества или вспомогательных процессов, таких как логистика;

- во всех случаях, когда на предприятиях организованы системы внутреннего аудита или внутреннего контроля непроизводственных процессов, такие системы не цифровизированы.

Сложившаяся ситуация, как показывают материалы проведенного нами выборочного полуструктурированного интервью с отдельными участниками анкетирования, связана отчасти с нехваткой организационного и финансового ресурса, но, как правило, основная проблема заключается в недостаточном понимании руководством и/или собственниками значимости организации интегративного контроля и его потенциальных преимуществ для развития бизнеса и повышения конкурентоспособности. Речь идет, при этом, о крупнейших предприятиях отраслей обрабатывающей промышленности, на малых и средних предприятиях ситуация обстоит намного хуже.

\section{ЛИТЕРАТУРА}

1. Борисов, С. А. Управление затратами и контроллинг: учебное пособие / С. А. Борисов, К. И. Колесов, А. Ф. Плеханова.—Нижний Новгород: Нижегородский государственный технический университет им. Р. Е. Алексеева, 2017. - 167 с.

2. Белозерова Л. А. Роль и значение внутреннего контроля в деятельности организации // Молодой ученый. — 2019.— № 24. — C. 316-320.— URL https:// moluch.ru/archive/262/60616/

3. Долганова Н.А., Тришкина Н. А., Аналитические исследования как основа принятия эффективных управленческих решений // Сборник IV Международной научно-практической конференции «Техника и технологии, политика и экономика: проблемы и перспективы» Коломенский БОУ ВПО «Московский государственный машиностроительный университет (МАMИ), — Коломна, 2017. - 248 c. ISBN978-5-905529-45-0

4. Задорнов К.С. Развитие методических подходов к формированию системы контроллинга на промышленных предприятиях: Дисс. канд. эконом наук: 08.00.05. - M., 2016. - 137c.

5. Козлова, Е. В. Интегрированное планирование: концепция, методология, организация: [монография] / Е. В. Козлова.—Саратов: Наука, 2014.— 100 с.

6. Хорошилова, О.В. Система интегрированного внутрифирменного планирования.—Воронеж: Воронежский гос. технический ун-т, 2011. — 193 с. 
7. Lasi H. et al. Industry 4.0 //Business \& Information Systems Engineering. — 2014. — Vol. 6. — N4. — P. 239-242.

8. Li D. et al. A big data enabled load-balancing control for smart manufacturing of Industry 4.0//Cluster Computing. — 2017. — Vol. 20.— N2. — P. 1855-1864.

9. Romero D., Vernadat F. Enterprise information systems state of the art: Past, present and future trends //Computers in Industry. — 2016. — Vol. 79. — P. 3-13.

10. Westerman G., Bonnet D., McAfee A. The Nine Elements of Digital Transformation [E-source]. URL:. https://sloanreview.mit.edu/article/the-nine-elements-ofdigital-transformation. Retrieved: June, 27, 2019.

(c) Горемыкина Татьяна Константиновна ( $5149611 @$ mail.ru ), Тришкина Надежда Антоновна ( ntrishkina@list.ru ).

Журнал «Современная наука: актуальные проблемы теории и практики»

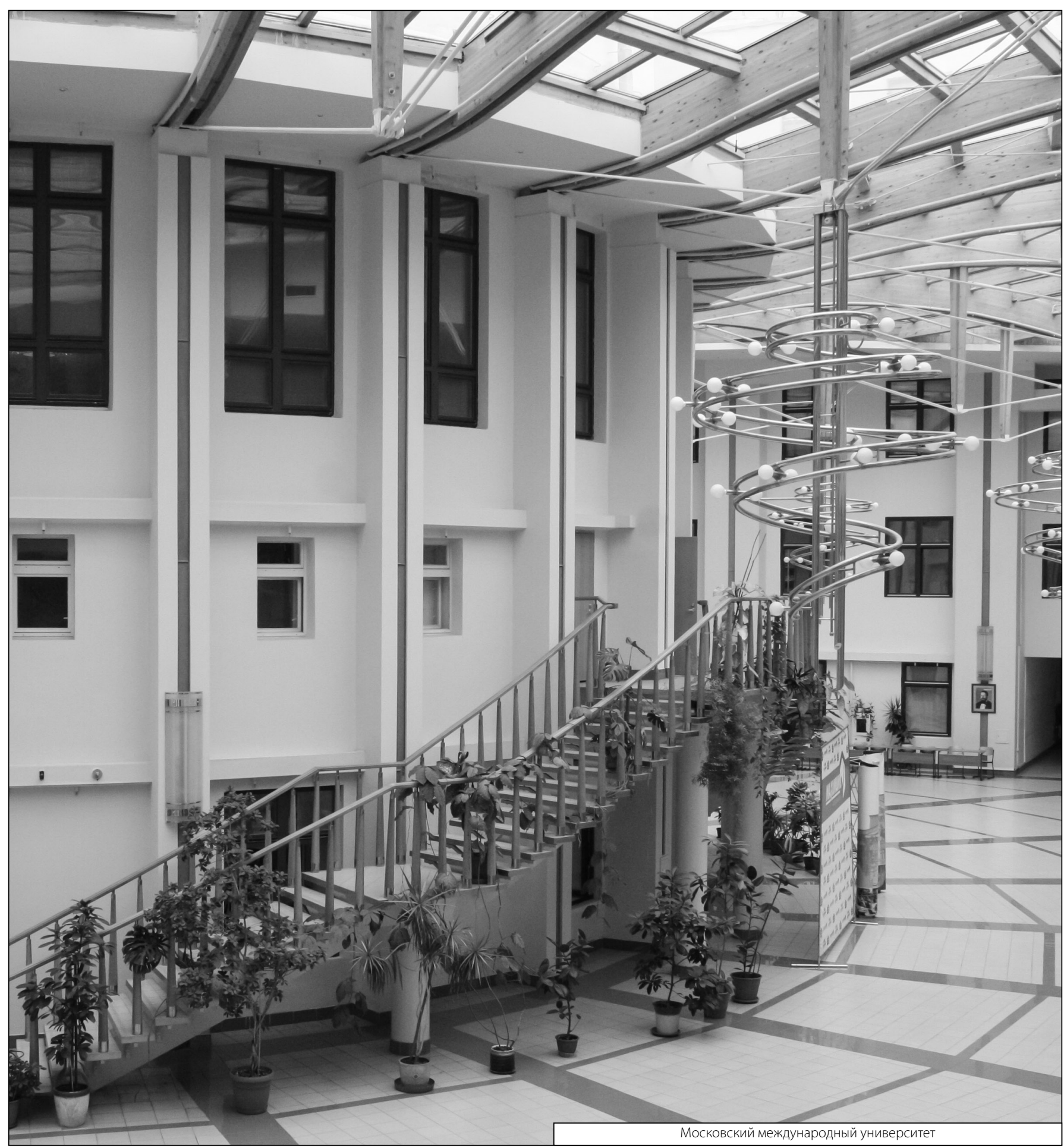

